\title{
A CONTRIBUIÇÃO DA REVISTA ESTUDOS FEMINISTAS PARA O DEBATE SOBRE GÊNERO E FEMINISMO
}

\author{
LUZINETE SIMÕES MINELLA \\ Universidade Federal de Santa Catarina
}

\begin{abstract}
Resumo: Este artigo objetiva refletir sobre a contribuição da Revista Estudos Feministas para o debate feminista, a partir de uma síntese dos textos publicados entre 1999 e 2000, ou seja, nos dois primeiros anos em que a Revista passou a ser sediada na Universidade Federal de Santa Catarina. Esta síntese tenta identificar os temas contemplados pela Revista, verificando os enfoques, as áreas disciplinares e os procedimentos metodológicos que têm sido utilizados nos artigos. Conclui-se que o conjunto das contribuições, não obstante sua diversidade epistemológica, revela primeiro, uma absorção acelerada de novas contribuições teóricas que tendem a relativizar as oposições binárias que fundamentaram a concepção clássica de ciência; segundo, um questionamento permanente dos dogmatismos e por último, a reafirmação contínua da força dos processos sociais e históricos no sentido de desestabilizar os paradigmas cientificos.

Palavras-Chave: estudos de gênero, estudos feministas, história das mulheres
\end{abstract}

Este artigo objetiva refletir sobre a contribuição da REF para o debate feminista, a partir de uma síntese dos textos publicados entre 1999 e 2000, ou seja, nos dois primeiros anos em que a Revista passou a ser sediada na Universidade Federal de Santa Catarina'. Esta síntese tenta identificar os temas contemplados pela Revista, verificando os enfoques (estudos de gênero e/ou feminismo, história e/ou estudos das mulheres), as áreas disciplinares e os procedimentos metodológicos que têm sido adotados pelas/os autoras/ es. Inicialmente, vale ressaltar que esta abordagem tem seus limites, primeiro, porque leva em conta apenas um determinado período da história da Revista, incluindo apenas três exemplares.

Segundo, porque do ponto de vista metodológico, a análise se baseia numa primeira leitura dos textos e dos resumos e ainda, na recuperação das informações relativas à formação e à instituição de origem das/os autoras/es, configurando-se portanto como uma abordagem preliminar, aproximativa, de nível descritivo, capaz apenas de fornecer algumas pistas para estudos mais aprofundados que podem ser elaborados posteriormente sobre as teorias e as metodologias. Mantive ao longo do texto a referência à formação e à instituição de origem, logo após o sobrenome das/os autoras/es.

Terceiro, porque embora a interpretação sobre os enfoques se baseie em indicações dadas pelas/os próprias/os autoras/es, percebo que no desenvolvimento das 
argumentações, as linhas que separam gênero de feminismo por exemplo, ou são muito tênues ou são muito pronunciadas, fato que mereceria uma análise mais detalhada. Dada a ausência de referências mais explícitas ao enfoque, em alguns casos, corro o risco, como sempre costuma ocorrer neste tipo de iniciativa, de cometer equívocos de interpretação. Por isto mesmo, a compreensão que apresento neste artigo, sobre os textos publicados na Revista dentro do período considerado, é transitória, altamente circunstanciada pela minha formação sociológica, devendo ser interpretada portanto, como apenas uma dentre as muitas leituras que os mesmos textos podem receber. ${ }^{2}$

Feitas estas ressalvas, parto de considerar, como pressuposto central da análise, que o surgimento da Revista resulta de um longo processo de maturação epistemológica e política, intensificado nos anos oitenta no Brasil em torno da questão feminina, como reflexo do debate internacional e da expansão das lutas e movimentos feministas. Levo em conta portanto, que desde as suas origens, e em razão desta tradição, a Revista Estudos Feministas tem mantido uma relação peculiar com o campo dos estudos feministas e das relações de gênero, atuando no sentido de modificá-lo e sendo simultaneamente metamorfoseada por ele.

Parto ainda de compreender que a Revista nasceu daquilo que denomino uma concepção feminista de edição, consciente de que preexistia uma cultura editorial hegemônica, contaminada por uma visão androcêntrica do diálogo acadêmico, mas esperançosa no sentido de entrar no jogo, estabelecendo um novo espaço para o pensamento feminista, e desenhando gradativamente, as novas e mutantes regras de sua divulgação.

Os exemplares que serão analisados constituem um bom exemplo desta relação. ${ }^{3}$ O exemplar de 1999, que inclui os números 1 e 2, contém na seção Artigos, diferentes abordagens disciplinares sobre distintos temas relevantes, apresentando inicialmente uma análise sociológica sustentada numa perspectiva de gênero, da inserção no mercado de trabalho das profissionais de prestígio - médicas, arquitetas, advogadas e engenheiras - elaborada por Cristina Bruschini e Maria Rosa Lombardi (ambas sociólogas da Fundação Carlos Chagas) a partir de dados secundários que constam nas RAIS (Relações Anuais de Informações Sociais do Ministério do Trabalho).

O segundo artigo ilustra o enfoque da história das mulheres, constituindo-se como uma detalhada análise feita por Maria Lúcia Mott (historiadora da FAE de São Paulo) sobre os estereótipos que contribuíram para reforçar a imagem da "parteira ignorante". A metodologia da investigação recupera dentre outros documentos, artigos, relatórios, memórias, teses, livros e tratados escritos por médicos, além de anúncios, correspondências, revistas, almanaques e processos do século XIX.

O texto de Maria Consuelo Cunha Campos (Literatura Brasileira da Universidade Estadual do Rio de Janeiro) por sua vez, aborda o transgênero e situa-se na interface entre os estudos culturais e a literatura, questionando - a partir da análise da situação de Roberta Close - o etnocentrismo e o sexismo presentes na institucionalização da identidade de gênero exigida nos documentos oficiais no Brasil. Para esclarecer os fundamentos de sua crítica às identidades fixas, essenciais e permanentes, a autora estabelece um paralelo entre esta situação e os argumentos da peça e do filme intitulados M. Butterfly.

O quarto artigo, escrito por Karen Giffin e Cristina Cavalcanti (socióloga e antropóloga respectivamente, da Escola Nacional de Saúde Pública da Fundação Oswaldo Cruz) se inscreve no âmbito dos estudos de gênero sobre o masculino e repensa do ponto de vista sócio-antropológico, com base numa revisão de literatura, a participação masculina no âmbito da reprodução, problematizando a sexualidade e a paternidade, discutindo o controle da fecundidade, as relações entre violência e gênero e a "feminização" da AIDS. 
O artigo de Simone Monteiro (profissional em Saúde Pública, Departamento de Biologia, Instituto Oswaldo Cruz/Fundação Oswaldo Cruz) relaciona, através da recuperação de várias contribuições dos campos da saúde coletiva, da sociologia e da antropologia, a questão da Aids com o cotidiano de jovens de um bairro popular, defendendo a necessidade de proteção da saúde sexual e reprodutiva na juventude. Trata-se de um estudo empírico, cuja metodologia se fundamentou na observação e na aplicação de um roteiro estruturado de entrevista que privilegiou os seguintes aspectos: o cuidado com a saúde, o significado da proteção e o uso do preservativo.

A partir de uma pesquisa empírica orientada para a recuperação dos aspectos simbólicos, no sexto artigo, Eliane Portes Vargas (Escola Nacional de Saúde Pública/ Fundação Oswaldo Cruz) destaca os aspectos relacionais de gênero, analisando do ângulo da Antropologia da Saúde, as representações de mulheres das camadas populares que buscam tratamento para engravidar, sobre fertilidade e infertilidade, discutindo o papel das novas tecnologias reprodutivas e o impacto da infertilidade sobre as relações conjugais e a identidade feminina.

Por último, o sétimo artigo, elaborado por Michèlle Barret (socióloga, City University, Londres) explora, de um ângulo feminista, as possibilidades da relativização tanto das palavras como das coisas, na análise feminista contemporânea, relacionando o pósestruturalismo e o pós-modernismo com o questionamento do materialismo e a abertura do feminismo para as questões culturais.

Sintetizando, verifica-se que dentre os sete artigos, prevaleceu a preocupação com a saúde (4), sendo que três dentre eles se dedicam à saúde reprodutiva. Do ponto de vista da metodologia da investigação, prevaleceram os estudos empíricos (3), observando-se apenas dois estudos estritamente teóricos. Quanto à vinculação disciplinar das autoras, tem-se três sociólogas, uma historiadora, três antropólogas, uma profissional com formação em literatura e uma com formação em saúde pública. Considerando-se os vínculos institucionais das autoras, verifica-se que dentre as nacionais, prevaleceram as contribuições da FIOCRUZ, através da Escola Nacional de Saúde Pública (o quarto e o sexto artigos) e do Instituto Oswaldo Cruz (o quinto artigo), registrando-se apenas uma instituição estrangeira, a City University de Londres.

Com relação ao enfoque, prevaleceu o gênero (4), contra dois que se sustentam em enfoques feministas, e apenas um deles pode ser situado no âmbito da História das Mulheres.

O dossiê deste exemplar, organizado pela antropóloga Bruna Franchetto, trata das mulheres indígenas, reunindo quatro contribuições produzidas no âmbito da Antropologia, que destacam o plano das representações do ângulo do gênero e do feminismo (Cristiane Lasmar, doutoranda do Museu Nacional da UFRJ, revisão de literatura); as habilidades produtivas e as diferenças de gênero entre os Kaxinawa (Cecília McCallum, UFBA, estudo etnográfico); as interseções entre gênero, divisão do trabalho, família, parentesco e concepção (Vanessa Rosemary Lea, PPG em Antropologia da UNICAMP, estudo etnográfico); e feminilidade e alteridade nas relações inter-étnicas com o surgimento das armas de fogo (Patrícia de Mendonça Rodrigues, Doutoranda da Universidade de Chicago, estudo etnográfico).

A seção Entrevista contém o diálogo estabelecido por Cláudia de Lima Costa (Estudos Culturais, UFSC) e Alai Garcia Diniz (Literatura Hispano-Americana, UFSC) com Mary Louise Pratt, professora de Literatura Latino-Americana e Literatura Comparada na Universidade de Stanford, Califórnia, Estados Unidos, explorando, dentre outros aspectos, a interseção entre as teorias feministas e o questionamento dos sistemas de gênero como fatores que desempenham atualmente um papel fundamental para qualquer perspectiva crítica. 
Na seção Ensaios constam duas contribuições: uma sobre a dominação masculina e outra sobre as relações entre família e gênero. A seção Resenhas divulga dez importantes pesquisas realizadas no Brasil e no exterior, incluindo várias áreas e temas: identidade política, história cultural, violência de gênero, gênero e ciência (2), religião, literatura de viagem, práticas narrativas e uma abordagem (crítica) literária sobre as escritoras brasileiras do século XIX.

No caso do número 1 de 2000, a seção Artigos inclui seis contribuições distintas. No primeiro deles, a partir de uma revisão de literatura, centrada numa perspectiva epistemológica, Susan R. Bordo (filósofa, Universidade de Kentucky, Estados Unidos) questiona até que ponto a teoria feminista continua sendo marginal em relação à teoria social contemporânea, argumentando que é necessário interpretar o feminismo como uma crítica à cultura, superando o entendimento de que a teoria feminista serviria apenas para interpretar as questões de gênero e as questões da mulher.

Na seqüência, Eli Bartra (também filósofa, Universidad Autónoma de México) propõe que a arte popular seja abordada a partir de um ponto de vista feminista, ilustrando esta proposta através da análise das friditas - recriações em barro e busto dos quadros de Frida Kahlo - feitas por Josefina Aguilar, artista popular mexicana.

O texto de Graciela L. Natansohn (doutoranda da UFBA na área de Comunicação) dedica-se a averiguar - através de uma perspectiva de gênero fundamentada na análise do discurso - as representações sobre médicos, saúde e enfermidade, mulher e papéis femininos presentes na mídia, em particular no Programa Mulher, da Rede Globo de Televisão.

No artigo seguinte, Nathalie Lebon (Estudos Feministas/Antropologia, RandolphMacon College, Virgínia, Estados Unidos) expõe os resultados de uma pesquisa empírica sobre as origens e características do movimento pela saúde da mulher no Estado de São Paulo, estabelecendo diferenças entre as organizações profissionalizadas e as não profissionalizadas para levantar algumas questões sobre as práticas políticas e a pluralidade organizacional feminista.

Escrito por Simone Pereira Schmidt, o quinto artigo (Teoria Literária, UFRGS) busca problematizar do ângulo de uma crítica literária feminista, a "representação romântica da identidade brasileira do século XIX, bem como levantar a questão de sua representatividade a partir do resgate de obras de autoria feminina silenciadas nas margens da tradição cultural brasileira e da sua inscrição no processo de narrativização da nação" 4 .

O último artigo, assinado por Françoise Héritier (antropóloga, africanista, Collège de France) leva a cabo uma leitura antropológica sobre os novos modos de procriação, revisando uma ampla literatura sobre o tema, a fim de problematizar as concepções de família, parentesco e filiação.

Contrabalançando o exemplar de 1999, conclui-se que, dentre os seis artigos, a maior parte deles - quatro - recupera a perspectiva feminista: dois do ângulo da Filosofia, um do ângulo da crítica literária e um a partir da análise dos movimentos feministas. Observa-se que apenas um deles explicita uma posição de gênero. Diferentemente do exemplar de 1999, primeiro, os estudos empíricos constituíram minoria (2) e segundo, a maioria das autoras é estrangeira (5), sendo que apenas uma delas reside no Brasil. Registrase portanto, a contribuição de quatro instituições estrangeiras: duas dos Estados Unidos, uma da França e uma do México.

Torna-se possível constatar também que a formação das autoras é variada, e contrasta com os dados verificados no exemplar anterior, (no qual prevaleceram sociólogas e antropólogas) tendo-se duas filósofas, uma profissional da área da Comunicação e uma que atua no âmbito da Teoria Literária. 
O dossiê aborda as relações entre gênero e saúde reprodutiva, contendo sete artigos, dois deles produzidos por autores latino-americanos que atuam no Colégio de México. Resultado de uma parceria entre duas profissionais de áreas distintas (Luzinete Simões Minella, Sociologia e Maria Juracy T. Siqueira, Psicologia, ambas da UFSC) o Dossiê inclui inicialmente a contribuição de Juan Guilhermo Figueroa-Perea, (filósofo, atua no campo de estudos sobre população do Colégio de México) que problematiza as relações entre os direitos reprodutivos e a experiência masculina no diálogo com o feminismo; em segundo lugar encontra-se a contribuição de Jorge Lyra e Benedito Medrado (Coordenador do Projeto PAPAI/UFPE e doutorando em Psicologia da UFPE/membro do PAPAI, respectivamente) que analisam os principais instrumentos de coleta de dados produzidos nas instituições do país para levantar uma série de questões acerca da invisibilidade da paternidade.

Posteriormente a pesquisa empírica de Siqueira problematiza a "participação masculina nas esferas da investigação, das intervenções e das políticas públicas na área de saúde reprodutiva" das mulheres provenientes dos segmentos de baixa renda sobre os serviços de planejamento familiar e sobre a participação masculina", objetivando construir novas hipóteses sobre as relações entre passividade e autonomia'.

O artigo de Ivonne Szasz (Ciências Sociais/Colégio de México) por sua vez, "analisa os significados da sexualidade e da identidade masculina entre homens mexicanos com base numa revisão da literatura existente sobre o tema, relacionando os resultados obtidos com os desafios que se impõem no campo da saúde reprodutiva"7.

No sexto artigo, fundamentado nos dados coletados através de pesquisa empírica, Maria das Dores Campos Machado (socióloga, UFRJ) analisa o modo como a mídia das igrejas pentecostais do Brasil tratou o tema do aborto, enquanto no último artigo Rosana Machin Barbosa (socióloga, UNIFESP) relaciona também a partir de pesquisa empírica gênero, infertilidade e novas tecnologias reprodutivas.

No âmbito do Dossiê, destacaram-se as pesquisas empíricas (quatro), cujos resultados visam oferecer subsídios para o desenvolvimento de ações na área. Comparando-se este Dossiê com o anterior, observa-se que foi dada uma ênfase maior ao enfoque de gênero, sendo que ambos recuperam principalmente a produção da academia sobre os temas abordados.

A entrevista, realizada por Bila Sorj (socióloga, Instituto de Filosofia e Ciências Sociais da UFRJ e Mirian Goldenberg (antropóloga da mesma instituição) com Hillary Wainwright (Filosofia, Políitica e Economia, Universidade de Manchester) aborda, dentre outros aspectos, o movimento de mulheres e a contribuição do feminismo para a Nova Esquerda.

A seção Ensaios contém duas contribuições: o desabafo de Gloria Anzaldúa sobre a invisibilidade das escritoras negras e lésbicas, e a reflexão de Débora Diniz (Antropologia, Universidade Nacional de Brasília) e Dirce Guilhem (Bioética, Universidade Nacional de Brasília) sobre feminismo, bioética e vulnerabilidade.

Por último, têm-se sete Resenhas que abordam os seguintes temas: o cotidiano das mulheres na floresta, a menopausa, a educação e a escola mista, as pedagogias da sexualidade, as narrativas feministas, o erotismo e a violência conjugal.

O segundo exemplar de 2000 inclui oito artigos. No primeiro deles, realizando uma revisão da literatura sobre o tema Linda Nicholson (História e Estudos da Mulher, Universidade de Washington) propõe uma reinterpretação do conceito de gênero, argumentando que, embora este conceito represente por um lado, um avanço significativo no que se refere à compreensão das diferenças entre as experiências culturais de homens e mulheres, por outro lado, não teria conseguido exorcizar a lógica binária que ainda orienta o 
pensamento, reforçando desta maneira os estereótipos culturais e dificultando o entendimento das condutas que desafiam os dualismos de gênero.

No segundo artigo, dialogando com os textos subseqüentes, Costa (Estudos Culturais, UFSC) reflete sobre as teorias feministas nas Américas e a política transnacional da tradução, levantando várias questões sobre rotas, conceitos fundacionais, fronteiras territoriais, institucionais e disciplinares, etc.

O texto de Francine Masiello (Literatura, Universidade da Califórnia, Berkeley) analisa, a partir do ângulo queer, as relações entre o periodismo cultural feminista e a crítica do sistema de gênero na economia Norte/Sul. Estas relações são construídas com base na análise do suplemento feminino de um jornal popular argentino.

No artigo subsequente, tomando como pano de fundo as teorias feministas e póscoloniais, Norma Klahn (Literatura, Universidade da Califórnia, Santa Cruz) discute as práticas escriturais chicanas a fim de tentar entender o diálogo entre mexicanas e chicanas como atitudes críticas frente aos discursos oficiais dos Estados mexicano e norte-americano. Refletindo sobre a circulação e a força do "imaginário cultural" mexicano (mitos e símbolos), a autora atribui à sua resignificação, o surgimento de práticas feministas descolonizadoras.

O artigo de Schmidt (Teoria Literária, UFSC) "discute sobre a produção e a recepção dos discursos sobre o feminismo no Brasil desde os anos 70 até os 90 " através da análise dos suplementos Folhetim e Mais do jornal Folha de São Paulo, "observando as transformações que foram sofrendo, de modo a reconstruir o percurso teórico delineado por trás dos discursos, bem como sua relação com o contexto político brasileiro"8.

No sexto artigo, Kia Lilly Caldwell (Antropologia Social, Estudos Africanos, Califórnia State Univeristy) "analisa a invisibilidade da raça e da experiência das mulheres negras" no campo nacional dos estudos da mulher. Fundamentando-se numa revisão das contribuições teóricas representadas pelos estudos da mulher em diferentes contextos geográficos e históricos (na Inglaterra, nos Estados Unidos e no Canadá), a autora "enfatiza a ausência da raça na maior parte dos estudos da mulher no Brasil", sugerindo que, para um melhor entendimento da diversidade, "é preciso dar um maior enfoque para a diferença racial e para a relação entre raça e gênero"?.

Na seqüência, Patrícia Zavella (Antropologia, Chicano/Latino Research Center, Universidade da Califórnia) comenta a difusão das teorias feministas nas Américas e a política transnacional da tradução, estabelecendo um diálogo com os artigos anteriormente citados de, Masiello, Klahn, Schmidt e Caldwell para concluir que estas autoras "desafiam vários ideais utópicos - ou seja, noções essencialistas de mulher, feminismo e mudança social - e apresentam significados específicos e complexos e práticas historicamente situadas"10.

Por último Nora Dominguéz (Teoria Literária, Universidade de Buenos Aires) defende a difusão de outras genealogias que funcionem como "relatos alternativos e contra hegemônicos" em relação à produção feminista hegemônica representada pelas autoras norte-americanas e européias. Segundo o entendimento da autora, a construção desta nova cartografia depende da resignificação do conceito de tradução, de modo a tornálo capaz de assumir um tom mais ativo e dinâmico, a partir do qual seja possível pensar os diferentes lugares.

Sintetizando, constata-se que nesta seção à semelhança do exemplar anterior, prevaleceu o enfoque feminista mas, desta vez, sobre outros temas: tradução, periodismo cultural, práticas escriturais, invisibilidade das mulheres negras, difusão de teorias feministas, etc. As metodologias incluem basicamente a análise do discurso e a crítica literária. No caso da formação disciplinar das autoras destacam-se as áreas vinculadas à Literatura e 
aos Estudos Culturais (5), tendo-se em seguida a Antropologia (2). Quanto às instituições de origem, predominam as estrangeiras (seis) contra duas nacionais.

Na seção Ensaio, Josefina Fernández (Antropologia) apresenta uma instigante interpretação das tensões entre o pensamento de Foucault e o feminismo. Dentre as principais contribuições de Foucault para as teorias feministas, a autora destaca "a desconstrução da subjetividade e a crítica a formas históricas de constituição das identidades". As tensões resultariam dos supostos normativos presentes nas próprias teses de Foucault sobre a dominação e as práticas de liberação ${ }^{1}$.

A entrevista, realizada por José Gatti (Estudos de Cinema/Comunicação, UFSC) com James Green, resgata a história da homossexualidade no Brasil, referindo-se dentre outros aspectos, à obra Além do carnaval: a homossexualidade masculina no Brasil do século $\mathrm{XX}$, ao movimento homossexual, às novas parcerias civis, etc.

O dossiê, organizado em parceria por Sonia Alvarez (Ciência Política, Universidade da Califórnia), Marlene Libardoni (Economista, Organização Não Governamental AGENDE) e Vera Soares (Educação, AGENDE) retoma a vinculação desta seção da Revista com o movimento, abordando do ângulo da "advocacy feminista" as ações afirmativas, iniciandose com a reflexão feminista de Virgínia Vargas Valente (Sociologia Política, Centro de la Mujer Peruana Flora Tristán) sobre a cidadania como "eixo de ação e reflexão do movimento feminista e ao mesmo tempo como uma das preocupações democráticas do final do século, a níveis nacionais e, como nunca antes, a nível global"12.

O texto de Magdalena Léon (Sociologia, Universidade de Colombia/FLACSO, Equador) discute as relações das mulheres com o poder, compreendendo que a utilização do termo "empoderamiento" pelo movimento de mulheres "configura-se como uma estratégia que busca impulsionar mudanças na vida cotidiana das mulheres e implementar um processo de transformações na estruturas sociais" ${ }^{13}$.

Em seguida Libardoni reflete sobre o conceito de advocacy, argumentando que este se encontra ainda em construção e que o seu significado "varia conforme o contexto social e político de cada nação", dependendo dos processos de tradução política. Conforme a autora, "advocacy feminista na América Latina é um fazer nitidamente político que requer rediscutir o papel do Estado e da sociedade civil na construção democrática e ao mesmo tempo exige repensar as estratégias de incidência feminista na promoção das transformações políticas, econômicas e culturais" ${ }^{14}$.

O artigo de Ana Cristina González Vélez (Saúde Reprodutiva e Sexualidade, Organização não Governamental SISMA-MUJER, Colombia) "desenvolve distintas definições sobre advocacy e as relaciona com concepções da política propondo uma definição que dê conta das distintas formas de influência no mundo público"15.

Na seqüência, Edna Maria S. Roland (Psicologia, Organização não Governamental FALA PRETA) discute as ações políticas e as instâncias de poder, defendendo que "a legitimidade de um processo de advocacy será dada pela manutenção de laços profundos a unir os setores globalizados com os setores em permanente e profundo convívio íntimo com aqueles que permanecem à margem", revertendo desta maneira, "em nossa própria prática política, a lógica da desigualdade e da exclusão”16 (2000, n.2, p. 239).

No penúltimo artigo, Fátima Pacheco Jordão (socióloga, Conselho da Condição Feminina de São Paulo) aborda o desenvolvimento de estratégias e táticas de comunicação no âmbito da mídia de massa, considerando indispensável que os movimentos tenham acesso às tecnologias midiáticas do mundo moderno e aprendam a utilizá-las criativamente para canalizar e divulgar suas demandas.

Por último, Márcia Laranjeira Jácome (Jornalista, ONG SOS Corpo) aborda o processo de criação da Campanha de Prevenção do Câncer Cérvico-Uterino, no cenário político 
local, "enfocando os processos de criação e desenvolvimento de cada uma das estratégias e seus impactos sobre as políticas locais de combate à doença"17.

Diferentemente dos dois dossiês anteriores, estes últimos textos refletem sobre as práticas políticas locais, preocupando-se com o registro e a contextualização das ações, elaborando um balanço do seu alcance e das suas limitações e problematizando o próprio conceito de advocacy. De uma maneira geral, os textos são propositivos e ao realizar um balanço das memórias locais, acabam fornecendo vários elementos para revitalizar as teorias.

As resenhas mantém seu compromisso com a diversidade de autoras/es, contextos, temas e orientações teórico-metodológicas, contemplando o universo feminino das cartas e da literatura, o feminismo queer, a saúde reprodutiva, as relações entre gênero e feminismo, gênero e dança, a história das mulheres na Argentina, e ainda, das mulheres revolucionárias na década de 30 .

Muita coisa pode ser dita sobre o conjunto destas contribuições que constam nos exemplares contemplados neste estudo preliminar, dependendo do lugar da enunciação. Os comentários a seguir, longe de esgotarem o assunto, pretendem apenas ressaltar os aspectos que me pareceram mais evidentes, deixando para um momento posterior uma reflexão mais acurada que seja capaz de levar em conta outros aspectos, de modo que se tenha melhores condições para dimensionar a contribuição da REF para o debate feminista a partir de um horizonte mais amplo que inclusive contemple uma quantidade maior de exemplares.

Os comentários se justificam na medida em que entendo, de acordo com os/as autores/as pós-modernos/as, que as práticas científicas devem se transformar num tema para si mesmas, colocando permanentemente em questão os elementos teóricos e empíricos implícitos em sua própria organização e instrumentos, para reforçar seu distanciamento dos determinismos e seu rompimento com uma visão unificada de ciência. Portanto, com a possibilidade de construção de conceitos unificados, universalmente válidos.

Por enquanto vale a pena assinalar primeiro, que houve na Revista espaço para os mais diferentes temas, enfoques, tendências e instituições. Garantiu-se também o espaço para áreas disciplinares antes minoritárias, caso da Literatura e dos Estudos Culturais. Simultaneamente foi retomado o diálogo com os movimentos através do Dossiê, tradição que voltaria à tona no primeiro número de 2001 , intitulado Mulheres na Política, Mulheres no Poder, organizado por Miriam Pillar Grossi (Antropologia,UFSC) em parceria com Sônia Miguel (Sociologia, CFEMEA).

Embora seja muito difícil generalizar quando se considera a estruturação teórica dos textos, percebe-se um certo desprendimento das matrizes clássicas, seja no âmbito das teorias feministas, seja no âmbito das correntes teóricas de modo geral. O conjunto das contribuições revela uma absorção acelerada de novas contribuições e uma tendência para dialogar dentro do marco de uma intensa proliferação de discursos. Em meio a incessantes ruídos, pode-se dizer que esta produção não ficou surda. Pelo contrário, parece ter ampliado a capacidade de escutar. E mais: justamente esta produção incessante e multifacetada favoreceu (e continua favorecendo) uma vigilância epistemológica em relação aos dogmatismos e às polarizações que tanto marcaram o pensamento da modernidade, reafirmando continuamente a força dos processos sociais e históricos no sentido de desestabilizar os paradigmas científicos.

Influenciada pela visão de ciência característica da pós-modernidade, a maioria dos artigos analisados relativiza implícita ou explicitamente, as oposições que fundamentaram a concepção clássica de ciência: natureza e cultura; teoria e prática; 
objeto e contexto; indivíduo e coletividade; biológico e social; qualidade e quantidade; abstrato e concreto; masculino e feminino. Contribuindo para demolir "verdades" que justificaram durante séculos a opressão feminina, as desconstruções às quais se referem os artigos mencionados balizam a busca da superação dos limites políticos que foram sendo impostos não apenas às mulheres, mas a todos os segmentos marginais em relação a uma minoria adulta, masculina e branca. E ainda, em alguns casos, dos limites epistemológicos e políticos que foram se instalando no interior das próprias práticas feministas. Variadas posições teóricas se unem portanto, em torno de certas rupturas fundamentais promovendo o avanço do debate.

Do ponto de vista da conceituação, à primeira vista tem-se a impressão de que existe um certo caos teórico, pois se atribui aos conceitos básicos da área (gênero, por exemplo), múltiplos significados. Simultaneamente observa-se que o termo feminismo tampouco funciona como uma categoria monolítica, aparecendo ora como política, ora como movimento social, ora como teoria, filosofia, etc. Dependendo do ângulo de análise, o gênero é interpretado ora como desdobramento do feminismo, ora como categoria que inclui o feminismo. O feminismo por sua vez, ora aparece como algo que inclui o gênero, ora como categoria que ultrapassa o gênero. Compreende-se que talvez esta multiplicidade de interpretações deva-se primeiro, ao próprio contexto de instabilidade da produção científica da pós-modernidade, dado o rompimento deste contexto com a pretendida identificação entre o real e o racional defendida pela modernidade. Dado ainda o fato de que este contexto admite e até defende, uma certa (des)ordem dos discursos científicos, ou seja, uma certa autonomia dos conceitos e das metodologias em relação às teorias que os engendraram, compreendendo que eles migrem de um lado para o outro, e que entrem desta maneira, numa cadeia intensamente produtora de novas hipóteses e de novas idéias.

Finalizando, sobre as metodologias, vários comentários poderiam ser elaborados. Ressalto apenas, por enquanto, que no plano dos estudos empíricos (realizados prioritariamente pelos textos que se incluem nas áreas da Sociologia e da Antropologia) observou-se a ênfase no retorno ao senso comum, dedicando-se as/os pesquisadoras/es a ouvir pessoas comuns que instaladas na sua cotidianidade, desenvolvem na prática seus códigos de sociabilidade. Talvez (uma hipótese) desta insistência possa ser explicada em função do fato de que os significados das relações de gênero são reinventados, ao invés de repetidos na práxis diária, território no qual se estabelecem as lutas e as negociações entre os diferentes sujeitos. Porque é na esfera da cotidianidade que se constituem os sujeitos. Porque a ciência não chega antes, mas depois do senso comum, tendo que correr atrás dele, desvendá-lo, decodificá-lo, construindo certos parâmetros que retornarão a esta mesma esfera (do senso comum), num diálogo permanente que impulsiona um caminho, segundo Boaventura de Sousa Santos, "para uma nova relação entre a ciência e o senso comum, uma relação em que qualquer deles é feito do outro e ambos fazem algo de novo"18.

\section{Notas}

Copyright (c) 2004 by Revista Estudos Feministas.

${ }^{1}$ Trabalho apresentado durante a programação da REDEFEM (Rede Brasileira de Estudos e Pesquisas Feministas), II Fórum Social Mundial, Porto Alegre/RS, Faculdade de Educação da Universidade Federal do Rio Grande do Sul, 02 de fevereiro de 2002.

${ }^{2}$ Considera-se ainda, que o envolvimento atual da autora com a editoria da Revista, tanto facilita quanto dificulta a realização deste balanço geral, dada por um lado, a posição privilegiada que esta condição proporciona no sentido do contato com a produção de ponta na área, e por outro em virtude do grau de 


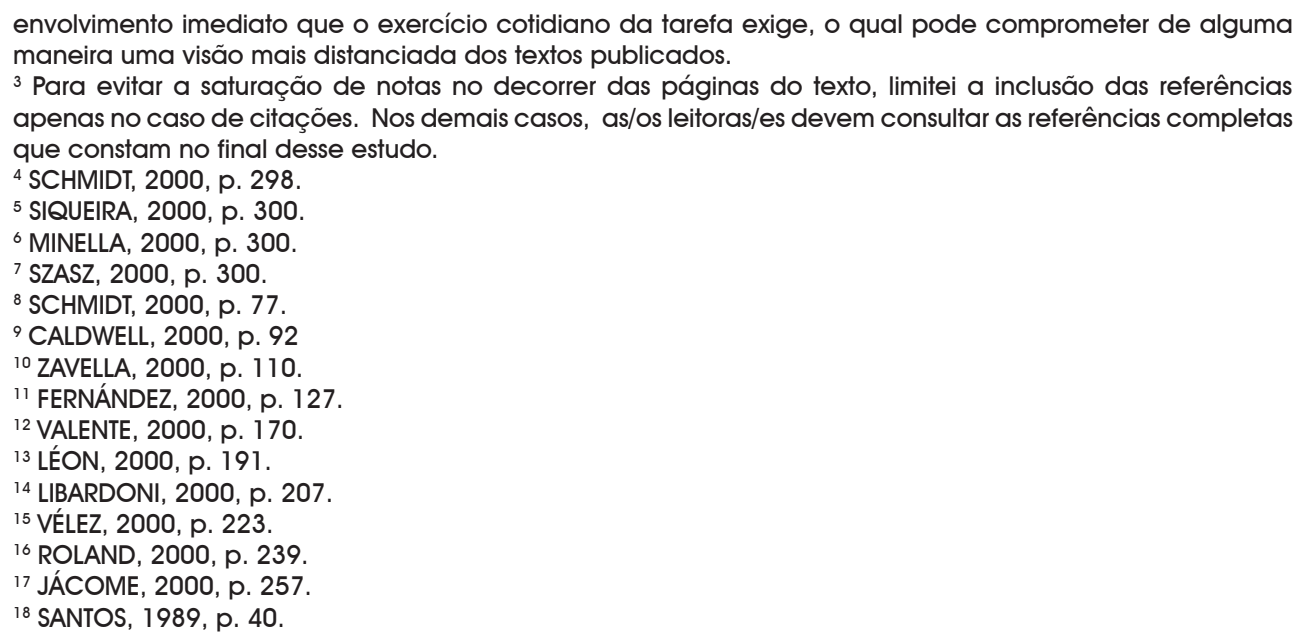

\section{Referências}

ANZALDÚA, Gloria. "Falando em línguas: uma carta para as mulheres escritoras do Terceiro Mundo." Revista Estudos Feministas, v. 8, n.1, p. 229-236, 1․ semestre, 2000.

BARBOSA, Rosana Machin. "Relações de gênero, infertilidade e novas tecnologias reprodutivas". Revista Estudos Feministas, v.8, n.1, p. 212-228, 1․ semestre, 2000.

BARRETT, Michèlle. "As palavras e as coisas: materialismo e método na análise feminista contemporânea". Revista Estudos Feministas, v.7, ns. 1 e 2, p. 109-126, 1999.

BARTRA, Eli. "Arte popular y feminismo". Revista Estudos Feministas, v.8, n. 1, p. 30-45, 1 . semestre, 2000.

BORDO, Susan R. "A feminista como o "Outro". Revista Estudos Feministas, v. 8, n. 1, p. 10 29, $1^{\circ}$. semestre, 2000.

BRUSCHINI, Cristina; LOMBARDI, Maria Rosa. "Médicas, Arquitetas, Advogadas e Engenheiras - mulheres em carreiras profissionais de prestígio". Revista Estudos Feministas, v.7, n. 1 e 2, p. 9-24, 1999.

CALDWELL, Kia Lilly. "Fronteiras da diferença: raça e mulher no Brasil". Revista Estudos Feministas, v. 8, n.2, p. 91-108, 2०. semestre, 2000.

CAMPOS, Maria Consuelo Cunha. "Roberta Close e M. Butterfly: trangênero, testemunho e ficção". Revista Estudos Feministas, v. 7, n. 1 e 2, p. 37-52, 1999.

COSTA, Claudia de Lima. "As teorias feministas nas Américas e a política transnacional da tradução". Revista Estudos Feministas, v. 8, n.2, p. 43-48, 2. semestre, 2000.

DINIZ, Débora; GUILHEM, Dirce. "Feminismo, bioética e vulnerabilidade". Revista Estudos Feministas, v. 8, n. 1, 237-244, $1^{\circ}$. semestre, 2000.

DOMINGUÉZ, Nora. "Diálogos del género o como no caerse del mapa". Revista Estudos Feministas, v. 8 n.2, p. $113-126,2^{\circ}$. semestre, 2000.

FERNÁNDEZ, Josefina. Foucault. "¿Marido o Amante? Algunas tensiones entre Foucault y el Feminismo". Revista Estudos Feministas, v. 8 n.2, 127-148, 2. semestre, 2000.

FONSECA, Tânia Mara. "A dominação masculina. Formas (in) sustentáveis de ser homem e mulher". Revista Estudos Feministas, v. 7, n.1 e 2, p. 206-213, 1999.

GATTI, José. "Mais amor e mais tesão: a história da homossexualidade no Brasil. Entrevista com James N. Green". Revista Estudos Feministas, v. 8, n. 2, p. 149-166, 2. semestre, 2000. 
GIFFIN, Karen; CAVALCANTI, Cristina. "Homens e Reprodução". Revista Estudos Feministas, v. 7, n.1 e 2, p. 53-71, 1999.

HÉRITIER, Françoise. 'A coxa de Júpiter'. Revista Estudos Feministas, v. 8, n. 1, p. 98-114, 1. semestre, 2000.

JÁCOME, Márcia Laranjeira. "Prevenção do câncer cérvico-uterino - uma política na cabeça, uma campanha em ação". Revista Estudos Feministas, v. 8, n.2, p. 257-268, $2^{\circ}$. semestre, 2000.

JORDÃO, Fátima Pacheco. "Desenvolvimento de estratégias e táticas de comunicação no Espaço da mídia de massa". Revista Estudos Feministas, v. 8, n.2, p. 243-256, 2. semestre, 2000.

KLAHN, Norma. "Travesias/Travesuras: des/vinculando imaginarios culturales". Revista Estudos Feministas, v. 8, n.2, p. 63-76, 2 . semestre, 2000.

LASMAR, Cristiane. "Mulheres Indígenas: representações". Revista Estudos Feministas, v. 7, n. 1 e 2, p. 143-156, 1999.

LEA, Vanessa Rosemary. "Desnaturalizando gênero na sociedade Mebengôkre". Revista Estudos Feministas, v. 7, n.1 e 2, p. 176-194, 1999.

LEBON, Nathalie. "Origens e desafios da profissionalização no movimento de saúde da mulher de São Paulo". Revista Estudos Feministas, v. 8, n. 1, p. 64-83, 1․ semestre, 2000.

LEÓN, Magdalena. "Empoderamiento: relaciones de las mujeres con el poder". Revista Estudos Feministas, v. 8, n.2, p. 191-206, 2०. Semestre, 2000.

LIBARDONI, Marlene. "Fundamentos teóricos e visão estratégica da Advocacy". Revista Estudos Feministas, v. 8, n.2, p. 207-222, $2^{\circ}$. semestre, 2000.

LYRA, Jorge; MEDRADO, Benedito. "Gênero e Paternidade nas pesquisas demográficas: o viés científico". Revista Estudos Feministas, v. 8, n. 1, p. 145-158, 1. semestre, 2000.

MACHADO, Maria das Dores Campos. "O tema aborto na mídia pentecostal: notas de uma pesquisa". Revista Estudos Feministas, v. 8, n. 1, p. 200-211, 1. semestre, 2000.

MASIELLO, Francine. "Conhecimento suplementar: queering o eixo norte/sul". Revista Estudos Feministas, volume. 8, n.2, p. 49-61, 2०. semestre, 2000.

McCALLUM, Cecília. "Aquisição de gênero e habilidades produtivas". O caso Kaxinawá. Revista Estudos Feministas, v. 7, n.1 e 2, p. 157-175, 1999.

MINELLA, Luzinete Simões. "Autodeterminação e passividade feminina e masculina no campo da saúde reprodutiva". Revista Estudos Feministas, v. 8, n.1, p. 169-187, 1. semestre, 2000.

MONTEIRO, Simone. "AIDS e Proteção: a visão de jovens de um bairro carioca". Revista Estudos Feministas, v. 7, n.1 e 2, p. 72-88, 1999.

MOTT, Maria Lúcia Barros. "A Parteira Ignorante: um erro de diagnóstico médico?". Revista Estudos Feministas, v. 7, n. 1 e 2, p. 25-36, 1999.

NATANSOHN, L. Graciela. "Medicina, gênero e mídia: o programa "Mulher" da TV Globo". Revista Estudos Feministas, v. 8, n. 1, p. 46-63, 1०. semestre, 2000.

NICHOLSON, Linda. "Interpretando o gênero". Revista Estudos Feministas, v. 8, n.2, p. 9-42, $2^{\circ}$. semestre, 2000.

PEREA, Juán Guilhermo Figueroa. "Derechos reproductivos y feminismo en la experiencia de los varones". Revista Estudos Feministas, v. 8, n.1, p. 131-144, 10. semestre, 2000.

RODRIGUES, Patrícia de Mendonça. "O Surgimento das Armas de Fogo: alteridade e feminilidade entre os Javaé". Revista Estudos Feministas, v. 7, n. 1 e 2, p. 195-205, 1999.

ROLAND, Edna Maria Santos. "Feminismo: Ações Políticas e Instâncias de Poder". Revista Estudos Feministas, v. 8, n. 2, p. 237-242, 2०. semestre, 2000.

SANTOS, Boaventura de Sousa. Introdução à uma ciência pós-moderna. $1^{a}$. ed. Rio de Janeiro: Graal, 1989. 
SCHMIDT, Simone Pereira. "O feminismo nas páginas dos jornais: revisitando o Brasil dos anos 70 aos 90". Revista Estudos Feministas, v. 8, n.2, p. 77-90, 2. semestre, 2000.

SCHMIDT, T. Rita. Mulheres reescrevendo a nação. Revista Estudos Feministas, v. 8 n. 1, p. 84-97, $1^{\circ}$. semestre, 2000.

SIQUEIRA, Maria Juracy Toneli. "Saúde e direitos reprodutivos: o que os homens têm a ver com isso?". Revista Estudos Feministas, v. 8, n. 1, p. 159-168, 1․ semestre, 2000.

SZASZ, Ivonne. "Varones mexicanos: género, sexualidad y salud reproductiva". Revista Estudos Feministas, v. 8, n. 1, p. 186-199, 1‥ semestre, 2000.

VALENTE, Virgínia Vargas. "Una Reflexión Feminista de la Ciudadania". Revista Estudos Feministas, v. 8, n. 2, p. 170-190, 2०. Semestre, 2000.

VARGAS, Eliane Portes. "A Figueira do Inferno": reveses da identidade feminina". Revista Estudos Feministas, v. 7, n.1 e 2, p.89-108, 1999.

VÉLEZ, González Ana Cristina. "Los Procesos de Influencia Política en el Campo de la Salud y los Derechos Sexuales y Reproductivos". Revista Estudos Feministas, v. 8, n.2, p.223236, $2^{\circ}$. semestre, 2000.

WADI, Yonissa Marmitt. "Olhar a família a partir das relações de gênero". Revista Estudos Feministas, v. 7, n.1 e 2 , p. 214-221, 1999.

ZAVELLA, Patricia. "Comentários sobre as teorias feministas nas América(s) Latina(s): a política transnacional da tradução". Revista Estudos Feministas, v. 8, n.2, p. 109-1 12, 2. semestre, 2000.

\section{The Contribution of Revista Estudos Feministas to Gender and Feminist Debates}

Abstract: This article proposes a reflection on the contribution of Revista Estudos Feministas (REF) to the gender and feminist debate, considering a synthesis of the texts issued in 1999 and 2000 , the first two years of the period in which REF is being edited in Universidade Federal de Santa Catarina. This synthesis tries to identify the themes discussed by REF, verifying viewpoints, fields of knowledge, and methodological proceedings that have been used in the articles. The conclusion is that the set of contributions at issue, notwithstanding its epistemological diversity, reveals, at first, an accelerated absortion of new theoretical contributions, which tend to relativize those binary oppositions that supported the classical conception of science; secondly a permanent challenge of dogmatism; and finally, a continual reiteration of the force of social and historical processes, aiming at destabilize scientific paradigms.

Keywords: gender studies, feminist studies, women's history 